\section{Colagens de futebol / Fußballcollagen}

\section{Michael Augustin}

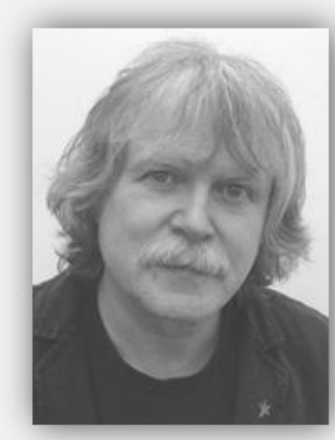

A revista FuLiA apresenta esta sensacional e inventiva série composta de seis desenhos sobre papel que representam o futebol de maneira deslocada da situação comum de jogo. As três primeiras imagens foram publicadas no livro do próprio autor - Fußball-

Miniaturen, Shoebox House Verlag, Hamburg, 2016 - e as três últimas são publicadas pela primeira vez.

Michael Augustin nasceu em Lübeck, em 1953, cidade localizada no estado de Schleswig-Holstein, no Norte da Alemanha. É escritor e editor de rádio em Bremen. Exerceu a função de escritor residente no Dickinson College (EUA), na Bath University (Inglaterra) e na Centro Heinrich Böll (Irlanda). Seus livros foram traduzidos para o inglês, irlandês, espanhol, italiano, grego e polonês. Estudou em Kiel e Dublin. Michael é membro honorário na redação da Universidade de Iowa e recebeu o Prêmio Friedrich Hebbel e o Prêmio Kurt Magnus.
Fußballcollagen ist ein Werk des 1953 in Lübeck, SchleswigHolstein, geborenen Künstlers Michael Augustin. Er ist Autor und Radioredakteur in Bremen. Er war Resident Writer am Dickinson College (USA), der Bath University (England) und Heinrich Böll (Irland). Seine Bücher wurden ins Englische, Irische, Spanische, Italienische, Griechische und Polnische übersetzt. Studierte in Kiel und Dublin. Michael ist Ehrenmitglied der Redaktion der University of Iowa und erhielt den Friedrich Hebbel Award und den Kurt Magnus Award.

Fußballcollagen ist eine Serie von sechs Zeichnungen auf Papier, die den Fußball in einer von der allgemeinen Spielsituation abweichenden Weise darstellen. Die ersten drei Bilder wurden im Buch des Autors veröffentlicht - FußballMiniaturen, Shoebox House Verlag, Hamburg, 2016 - und die letzten drei Bilder werden zum ersten Mal veröffentlicht. 


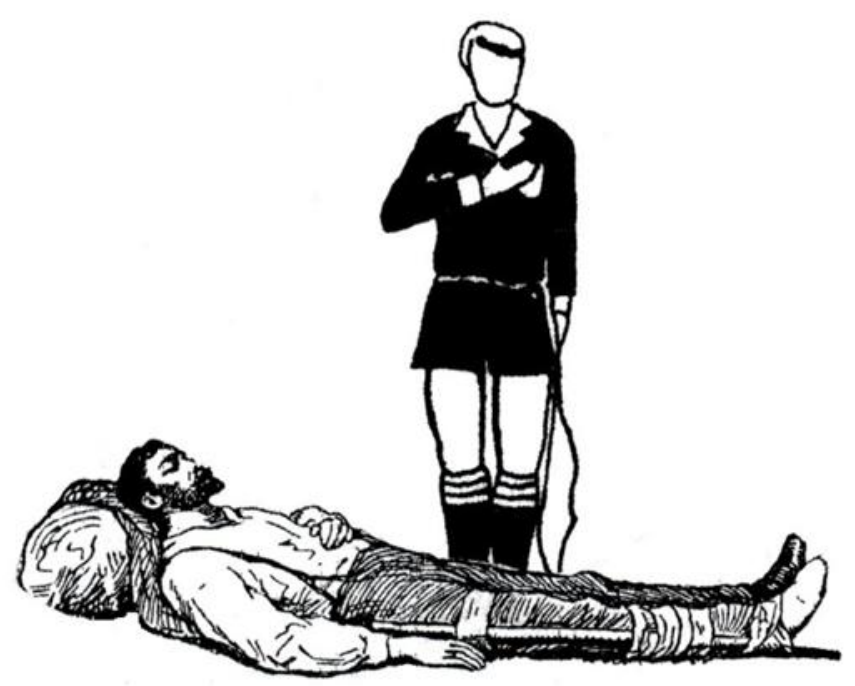




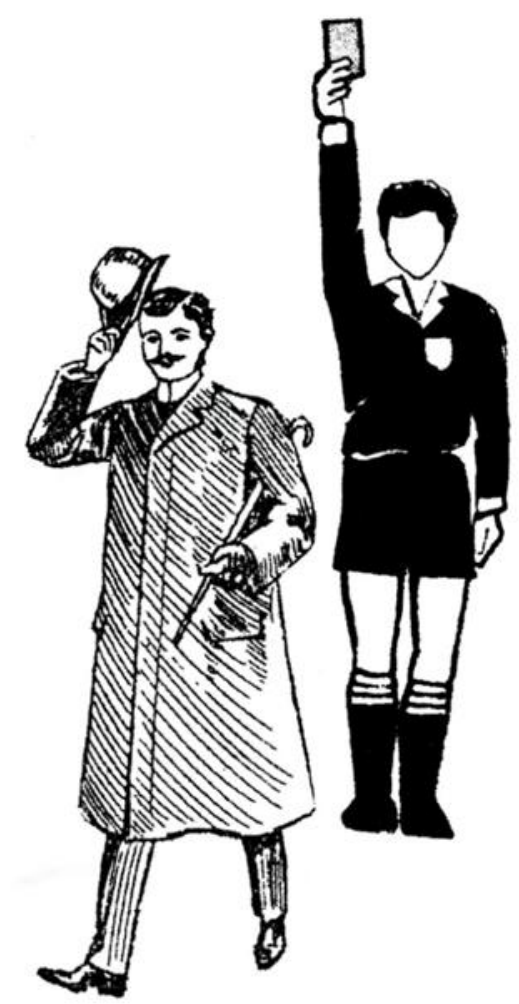

Herr mit Hut des Platzes verwiesen

(Homem de chapéu expulso de campo) $14,8 \mathrm{~cm} \times 21 \mathrm{~cm}$, papel 


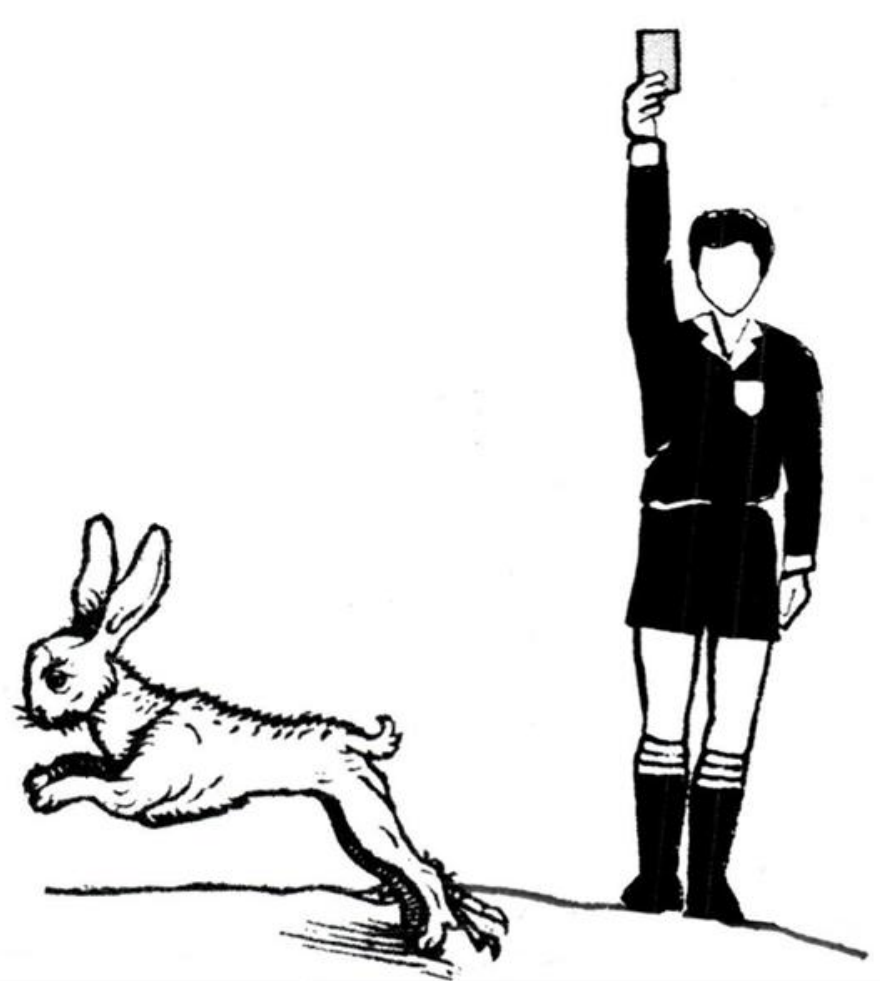

Angsthasenfußball

(Futebol e o medo do coelho) $21 \mathrm{~cm} \times 14,8 \mathrm{~cm}$, papel 


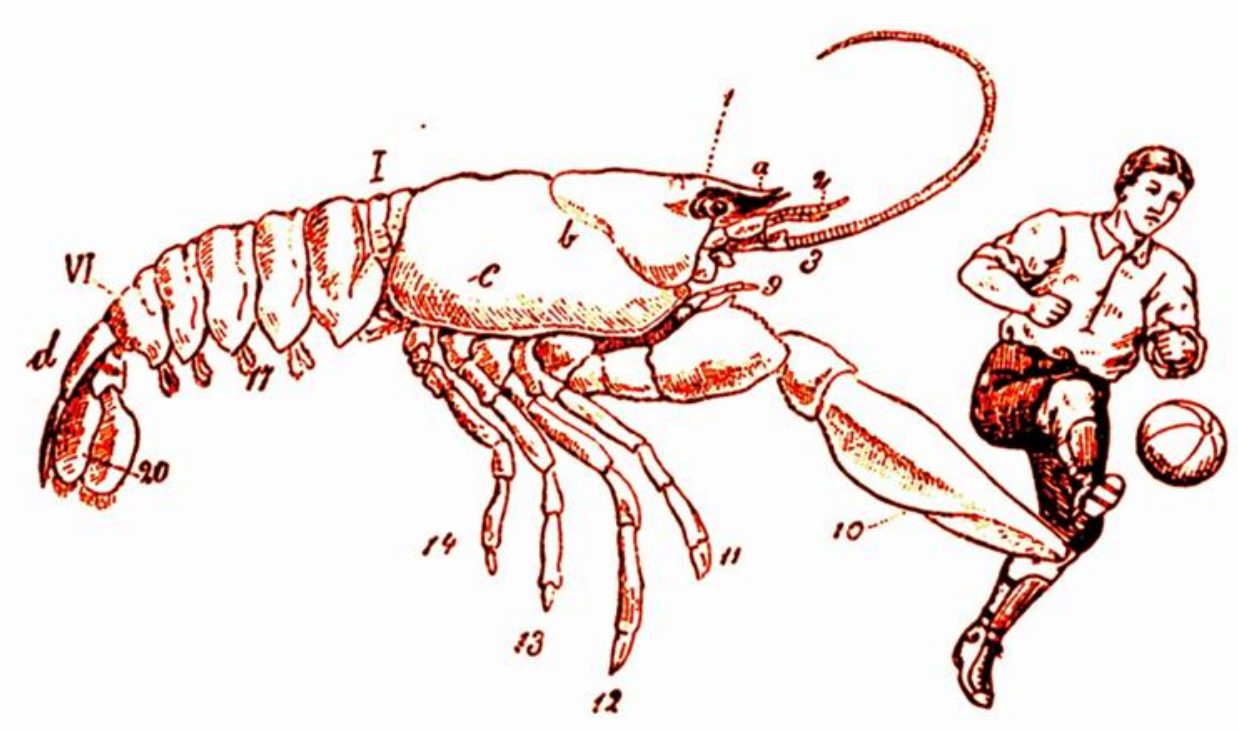




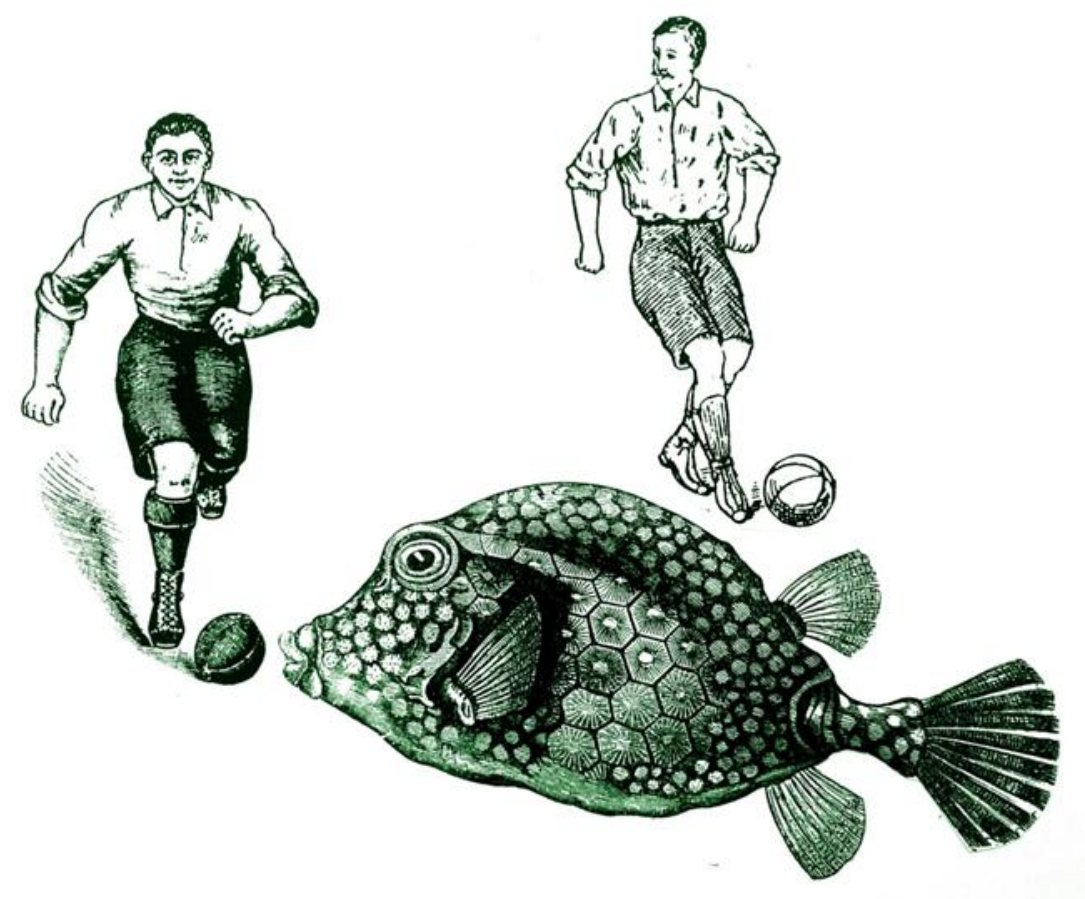




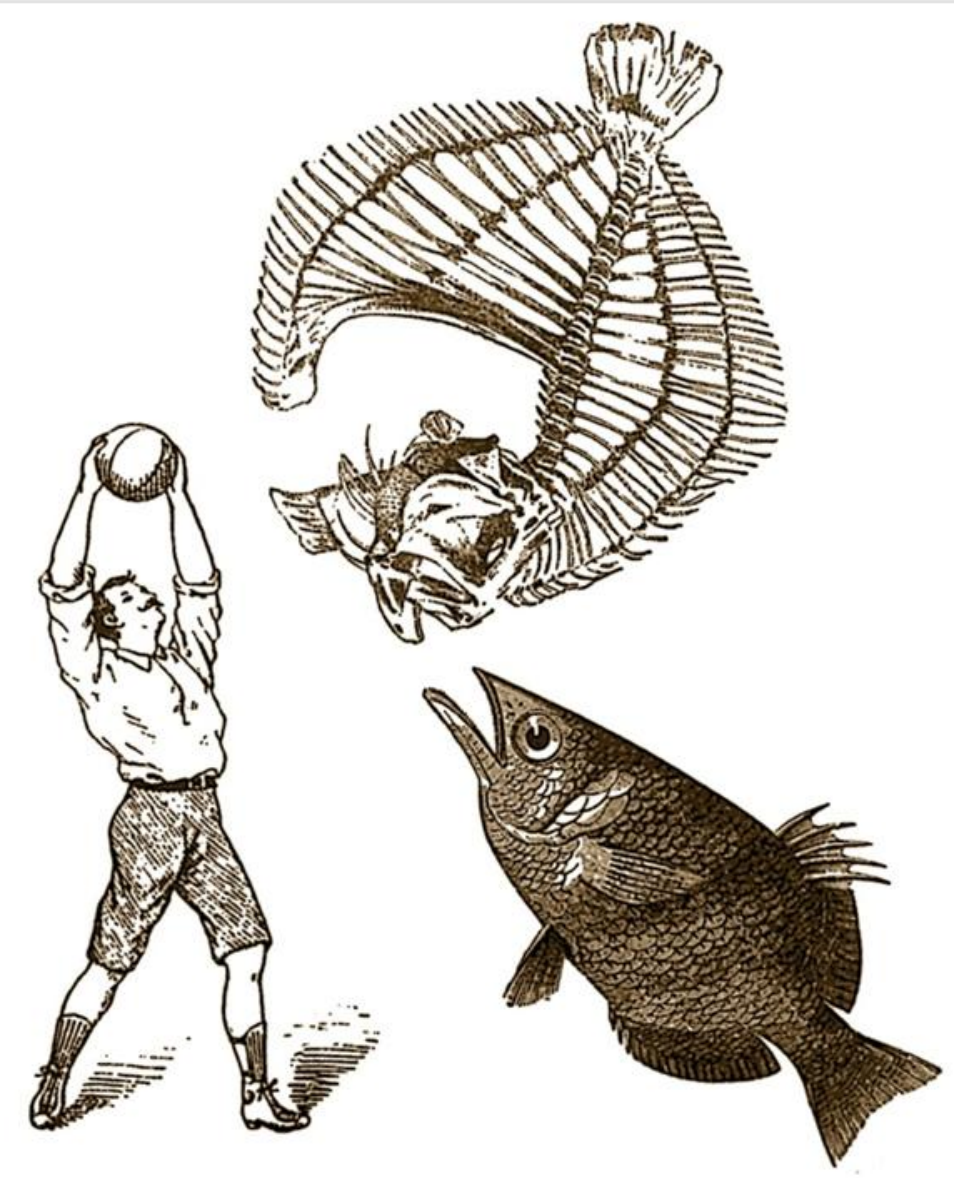

Arremesso errado! (Falscher Einwurf!) $29,7 \mathrm{~cm} \times 21 \mathrm{~cm}$, papel 